\title{
Primary spinal epidural cavernous hemangioma: clinical features and surgical outcome in 14 cases
}

\author{
Teng-yu Li, MD, 1,4 Yu-lun Xu, MD, PhD,1 Jun Yang, MD,1 James Wang, MD, ${ }^{2}$ \\ and Gui-Huai Wang, MD, $\mathrm{PhD}^{1,3}$
}

\begin{abstract}
1Department of Neurosurgery, Beijing Tiantan Hospital, Capital Medical University; ${ }^{3}$ Beijing Neurosurgical Institute, Capital Medical University; ${ }^{4}$ Department of Neurosurgery, Beijing Dongzhimen Hospital Eastern, Beijing University of Chinese Medicine, Beijing, China; and ${ }^{2}$ Department of Neurosurgery, Providence Medical Center, Seattle, Washington
\end{abstract}

\begin{abstract}
OBJECT The aim of this study was to investigate the clinical characteristics, imaging features, differential diagnosis, treatment options, and prognosis for primary spinal epidural cavernous hemangiomas.

METHODS Fourteen patients with pathologically diagnosed non-vertebral origin cavernous hemangiomas who had undergone surgery at Beijing Tiantan Hospital between 2003 and 2012 were identified in the hospital's database. The patients' clinical data, imaging characteristics, surgical treatment, and postoperative follow-up were analyzed retrospectively.
\end{abstract}

RESULTS There were 9 males and 5 females with an average age of 51.64 years. The primary epidural cavernous hemangiomas were located in the cervical spine (2 cases), cervicothoracic junction (2 cases), thoracic spine (8 cases), thoracolumbar junction (1 case), and lumbar spine (1 case). Hemorrhage was confirmed in 4 cases during surgery. Preoperatively 5 lesions were misdiagnosed as schwannoma, 1 was misdiagnosed as a meningioma, and 1 was misdiagnosed as an arachnoid cyst. Preoperative hemorrhages were identified in 2 cases. Three patients had recurrent cavernous hemangiomas. The initial presenting symptoms were local pain in 5 cases, radiculopathy in 6 cases, and myelopathy in 3 cases. Upon admission, 1 patient had radicular symptoms and 13 had myelopathic symptoms. The average symptom duration was 18 months. All patients underwent surgery; complete resection was achieved in 8 cases, subtotal resection in 4 cases, and partial resection in 2 cases. Postoperative follow-up was completed in 10 cases (average follow-up 34 months); 1 patient died, 5 patients showed clinical improvement, and 4 patients remained neurologically unchanged.

CONCLUSIONS Total surgical removal of spine epidural cavernous hemangiomas with a chronic course is the optimum treatment and carries a good prognosis. Secondary surgery for recurrent epidural cavernous hemangioma is technically more challenging. In patients with profound myelopathy from acute hemorrhage, even prompt surgical decompression can rarely reverse all symptoms.

http://thejns.org/doi/abs/10.3171/2014.9.SPINE13901

KEY WORDS cavernous hemangiomas; spinal epidural lesions; imaging features; surgical treatment; prognosis; vascular disorders

$\mathrm{S}$ PINAL epidural hemangiomas account for about $4 \%$ of all spinal epidural tumors and $12 \%$ of spinal cord vascular diseases. ${ }^{3,9,16}$ Spinal cavernous hemangiomas usually originate from vertebrae and invade the epidural space. Pure non-vertebral origin spinal epidural cavernous hemangiomas are relatively rare; so far only about 100 cases have been reported in the literature..$^{12,14}$ With the widespread use of MRI, the rate of discovery of spinal epidural hemangiomas has dramatically increased. ${ }^{6}$
Due to their tendency to spontaneously and intraoperatively bleed, as well as the probability of recurrence, spinal epidural hemangiomas should receive more attention from neurosurgeons. We report on 14 patients with pathologically diagnosed non-vertebral origin cavernous hemangiomas that were surgically at Beijing Tiantan Hospital between 2003 and 2012. We analyze the patients' clinical data, image characteristics, surgical treatment, and postoperative follow-up. 


\section{Methods \\ Patient Population}

We obtained consent from the institutional review board of Beijing Tiantan Hospital. Fourteen patients with pathologically diagnosed non-vertebral origin cavernous hemangiomas who had undergone surgery at Beijing Tiantan Hospital between 2003 and 2012 were identified in the hospital's database. Patients' clinical characteristics, MR images, and follow-up surgical results were retrospectively analyzed. The patients' symptoms were classified as local pain, radiculopathy, and myelopathy. ${ }^{1}$ The extent of resection was considered total, subtotal, or partial.

\section{Neurological and Imaging Assessment}

The Frankel grading system (Table 1) was used to evaluate the patients' neurological function. ${ }^{5}$ Functional assessments were conducted preoperatively, postoperatively, and during regular follow-up.

Imaging results were summarized according to the report provided by the Beijing Tiantan Hospital Neuroimaging Center, and the lesion shape was classified as having smooth, lobulated, or invasive contours. ${ }^{11}$

\section{Results}

\section{General Clinical Characteristics}

The general characteristics of the 14 patients ( 9 males and 5 females) are summarized in Table 2. The average patient age was 51.64 years (range 15-79 years). The lesions were located in the cervical spine in 2 patients, cervicothoracic junction in 2 patients, thoracic spine in 8 patients, thoracolumbar junction in 1 patient, and lumbar spine in 1 patient. Acute onset occurred in 3 cases, while the remaining 11 patients had a chronic clinical course. The initial symptoms were documented as local symptoms in 5 patients, radiculopathy in 6 patients, and myelopathy in 3 patients. On admission, only 1 patient still had radicular symptoms while the remaining 13 patients developed myelopathic symptoms. The average duration of preoperative symptoms was 18 months. At admission, 4 patients had myelopathic signs, 6 patients had sensory dysfunction, 6 patients had weakness, and 5 patients developed sphincter disturbances. In 3 patients with acute symptom onset from hemorrhage, symptoms included flaccid paralysis, sphincter disturbances, and clear sensory level below the injury plane.
Three patients experienced recurrence 14 years, 10 years, and 3 years after the original surgery. All 3 patients were found to have visible bone destruction, and their tumors adhered closely to surrounding tissue, without a clear border (Fig. 1).

\section{MRI Characteristics}

All patients underwent preoperative MRI with and without contrast (Table 3). Ten lesions were located in the dorsal spinal canal and 2 were in the ventral canal. The other 2 lesions were limited to the lateral portion of the spinal canal. In 9 cases, the tumor extended into the intervertebral foramen (5 lesions on the left side, 3 lesions on the right side, and 1 lesion bilaterally). Intramedullary abnormal signal was seen in 3 cases. On T1-weighted imaging, 2 tumors were hyperintense, 3 were hypointense, and 9 were isointense. On T2-weighted imaging, 10 lesions were hyperintense, 3 were hypointense, and 1 was isointense. In 11 cases, the tumors enhanced after Gd-DTPA administration (8 strongly enhanced). In 9 patients, the tumors showed a lobulated contour (Fig. 2).

\section{Preoperative Diagnosis}

Five tumors had been preoperatively diagnosed as schwannomas, 1 as meningioma, 1 as an arachnoid cyst, 2 as epidural hemorrhagic lesions, 3 as cases of recurrent epidural hemangioma, and 2 cases were diagnosed as spinal vascular malformations.

\section{Surgical Details}

All patients underwent surgery in the lateral decubitus position (left side up in 12 cases and right side up in 2 cases) via a posterior midline approach. In 2 patients with epidural hematoma, laminectomy was performed; hemilaminotomy was performed in 1 case, while the remaining patients (with the exception of the patients with recurrent lesions since the laminae had been previously removed) underwent laminoplasty.

The lesions were usually well circumscribed, dark red or purplish red and soft. The blood supply was rich and the tumor easily became bloody when touched by an instrument. The lesions shrank upon bipolar coagulation, which often can facilitate tumor dissection from the dura mater or nerve root. Generally abnormal proliferation of vascular malformation was seen; small feeding arteries and draining veins were visible. In one case, a large cystic mass was found in the dorsal and lateral spinal canal, with

TABLE 1. The Frankel grading system

\begin{tabular}{|c|c|}
\hline Grade & Definition \\
\hline A (complete) & No motor or sensory function clinically detected below the level of the injury \\
\hline B (sensation only) & $\begin{array}{l}\text { No motor function clinically detected below the level of the injury; sensory function remains below the level } \\
\text { of the injury but may include only partial function (sacral sparing qualifies as preserved sensation) }\end{array}$ \\
\hline C (motor useless) & Some motor function observed below the level of the injury, but is of no practical use to the patient \\
\hline $\mathrm{D}$ (motor useful) & $\begin{array}{l}\text { Useful motor function below the level of the injury; patient can move lower limbs \& walk w/ or w/o aid but } \\
\text { does not have a normal gait or strength in all motor groups }\end{array}$ \\
\hline $\mathrm{E}$ (normal motor) & $\begin{array}{l}\text { No clinically detected abnormality in motor or sensory function with normal sphincter function; abnormal } \\
\text { reflexes \& subjective sensory abnormalities may be present }\end{array}$ \\
\hline
\end{tabular}




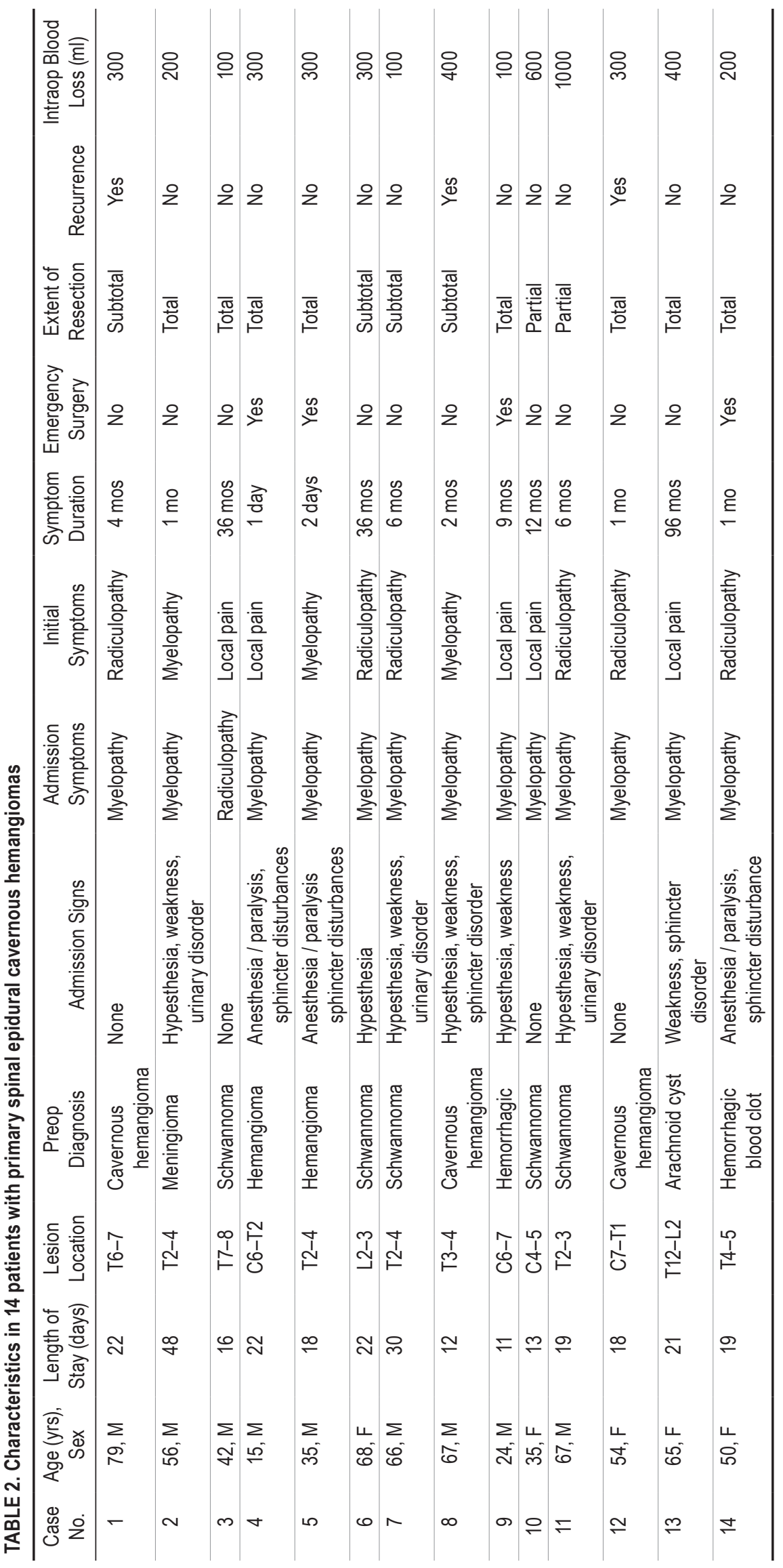




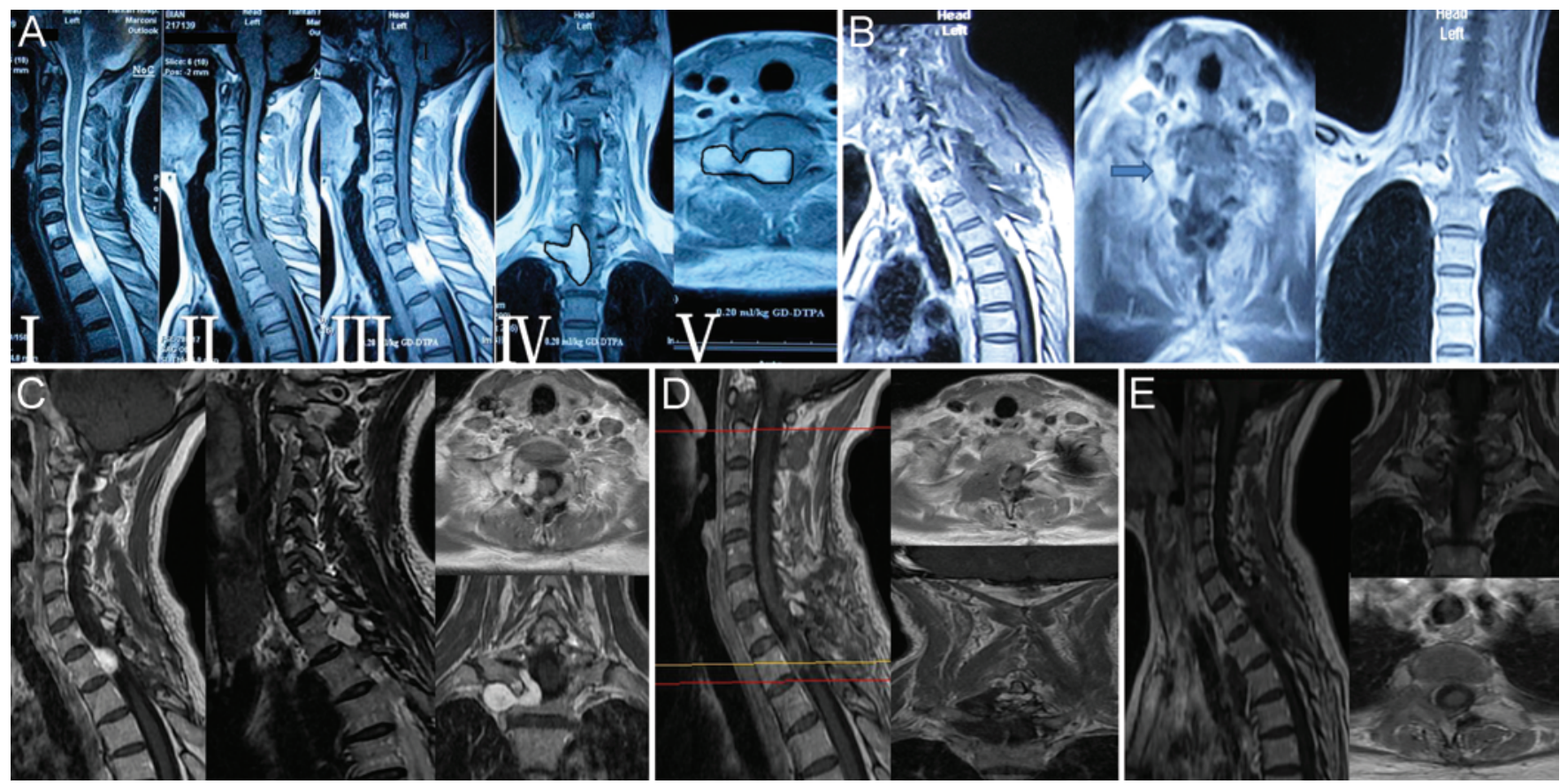

FIG. 1. Case 12. A: Preoperative MR images. The lesion appears homogeneously isointense on T1-weighted (II) and hyperintense on T2-weighted (I) images and homogeneously strongly enhancing after Gd-DTPA administration on T1-weighted images (III, IV, and V; the lesion is within the solid line). B: Postoperative T1-weighted MR images obtained before patient discharge, showing partial resection. The arrow indicates the residual tumor. C: Magnetic resonance images showing tumor recurrence 3 years later. The lesion extends to the intervertebral foramen and is adjacent to the pleura. D: Magnetic resonance images obtained after the second total resection. No enhancement after Gd-DTPA administration can be seen. The 2 lower lines indicate the levels that the axial cuts on the right were obtained. E: One year after the second surgery, Gd-DTPA MR images demonstrate no tumor recurrence. Figure is available in color online only.

a thick gray and tough hard cyst wall; the lesion adhered tightly to the dura and had a rich blood supply. Brownish cyst fluid was released after complete resection of the lesion (Fig. 3). In another case the lesion was polycystic with visible yellowish discoloration of the surrounding tissue. Hemorrhages were identified in 4 patients intraoperatively, including 2 patients with perilesional/epidural hematomas (Fig. 4) and 2 patients with intralesional hematoma.

\section{Extent of Resection}

Total resection was achieved in 8 patients, and partial resection was done in 2 patients due to the vigorous bleeding encountered during the surgery. In both cases surgery was terminated after the hemorrhage was controlled with Gelfoam sponge rolls. In 2 cases, the tumor extended far out of the neuroforamen, so only subtotal resection was achieved. In the 3 cases of recurrence, the tumors were found to closely adhere to the surrounding tissue without a clear border.

\section{Follow-Up}

Postoperative follow-up was completed in 10 patients (Table 4), with an average of 34 months of follow-up. One patient died of pulmonary complications due to a longterm condition that rendered him bedridden, 5 patients demonstrated significant clinical improvement, and 4 patients remained neurologically unchanged, including all 3 acutely paraplegic patients.

\section{Discussion}

Cavernous hemangiomas can be found in multiple systems of the body. ${ }^{3}$ Spinal cavernous hemangiomas are relatively rare; the majority originate from the vertebral body and extend into the epidural space. A pure spinal epidural cavernous hemangioma is rare.

The male-to-female ratio of this group was 1.8:1 (9/5), with a clear male predominance, which is different from previous reports in the literature., ${ }^{917}$ The average patient age in our group was 51.64 years (range 15-79 years), confirming the previous reports that epidural cavernous hemangioma is a rare condition in the pediatric population. ${ }^{13}$ The tumors were more commonly located in the thoracic spine than in the cervical spine, which is in general agreement with the literature., ${ }^{4,6}$

On admission, more patients had myelopathic symptoms (13 patients) than radicular symptoms (1 patient), proving that the nerve root can tolerate long-term soft compression much better than the spinal cord. Most patients with epidural cavernous hemangiomas have a chronic clinical course (18 months), with symptoms gradually worsening over several months. This may be associated with small intralesional hemorrhages and embolism, the proliferation of blood vessels caused by hormones, or poor venous return. ${ }^{8,9}$ In most studies, 3 different modes of manifestation are distinguished: acute hemorrhage into the lesion, acute hemorrhage surrounding the lesion; and slow seeping hemorrhage. ${ }^{13}$ Polycystic lesions seen during surgery may 
TABLE 3. Preoperative MRI findings in all patients

\begin{tabular}{|c|c|c|c|c|c|c|c|c|c|c|}
\hline $\begin{array}{l}\text { Case } \\
\text { No. }\end{array}$ & T1-Weighted & T2-Weighted & Enhancement & Location & $\begin{array}{c}\text { Intervertebral } \\
\text { Foramen } \\
\text { Extension }\end{array}$ & $\begin{array}{l}\text { Vertebral } \\
\text { Destruction }\end{array}$ & $\begin{array}{l}\text { Intramedullary } \\
\text { Abnormal } \\
\text { Signal }\end{array}$ & Contour & $\begin{array}{c}\text { No. of } \\
\text { Vertebral } \\
\text { Segments }\end{array}$ & Rim \\
\hline 1 & Iso & Hyper & $\begin{array}{l}\text { Heterogeneous, } \\
\text { obvious }\end{array}$ & Dorsal & Left & Yes & No & Lobulated & 2 & No \\
\hline 2 & Iso & Hyper & $\begin{array}{l}\text { Homogeneous, } \\
\text { obvious }\end{array}$ & Dorsal & Left & Yes & No & Lobulated & 3 & No \\
\hline 3 & Нуро & Hyper & Heterogeneous & Dorsal & None & No & No & Smooth & 2 & No \\
\hline 4 & Iso & Нypo & None & Dorsal & None & No & Yes & Smooth & 4 & No \\
\hline 5 & Hyper & Hypo & Marginal & Dorsal & None & No & No & Smooth & 3 & No \\
\hline 6 & Нypo & Hyper & $\begin{array}{l}\text { Homogeneous, } \\
\text { obvious }\end{array}$ & Left & Right & No & No & Lobulated & 2 & Yes \\
\hline 7 & Iso & Hyper & $\begin{array}{l}\text { Homogeneous, } \\
\text { obvious }\end{array}$ & Dorsal & Right & No & Yes & Lobulated & 3 & Yes \\
\hline 8 & Iso & Hyper & Homogeneous & Ventral & Left & Yes & No & Lobulated & 2 & No \\
\hline 9 & Hyper & Hypo & None & Dorsal & None & No & No & Smooth & 2 & No \\
\hline 10 & Iso & Hyper & $\begin{array}{l}\text { Heterogeneous, } \\
\text { obvious }\end{array}$ & Left & Left & Yes & No & Lobulated & 2 & Yes \\
\hline 11 & Iso & Hyper & $\begin{array}{l}\text { Homogeneous, } \\
\text { obvious }\end{array}$ & Dorsal & Left & No & No & Lobulated & 2 & Yes \\
\hline 12 & Iso & Hyper & $\begin{array}{l}\text { Homogeneous, } \\
\text { obvious }\end{array}$ & Ventral & Right & Yes & No & Lobulated & 2 & No \\
\hline 13 & Нypo & Hyper & None & Dorsal & Bilateral & No & No & Lobulated & 3 & Yes \\
\hline 14 & Iso & Iso & $\begin{array}{l}\text { Heterogeneous, } \\
\text { obvious }\end{array}$ & Dorsal & None & No & Yes & Smooth & 3 & Yes \\
\hline
\end{tabular}

Hyper = hyperintense; Hypo = hypointense; Iso = isointense.
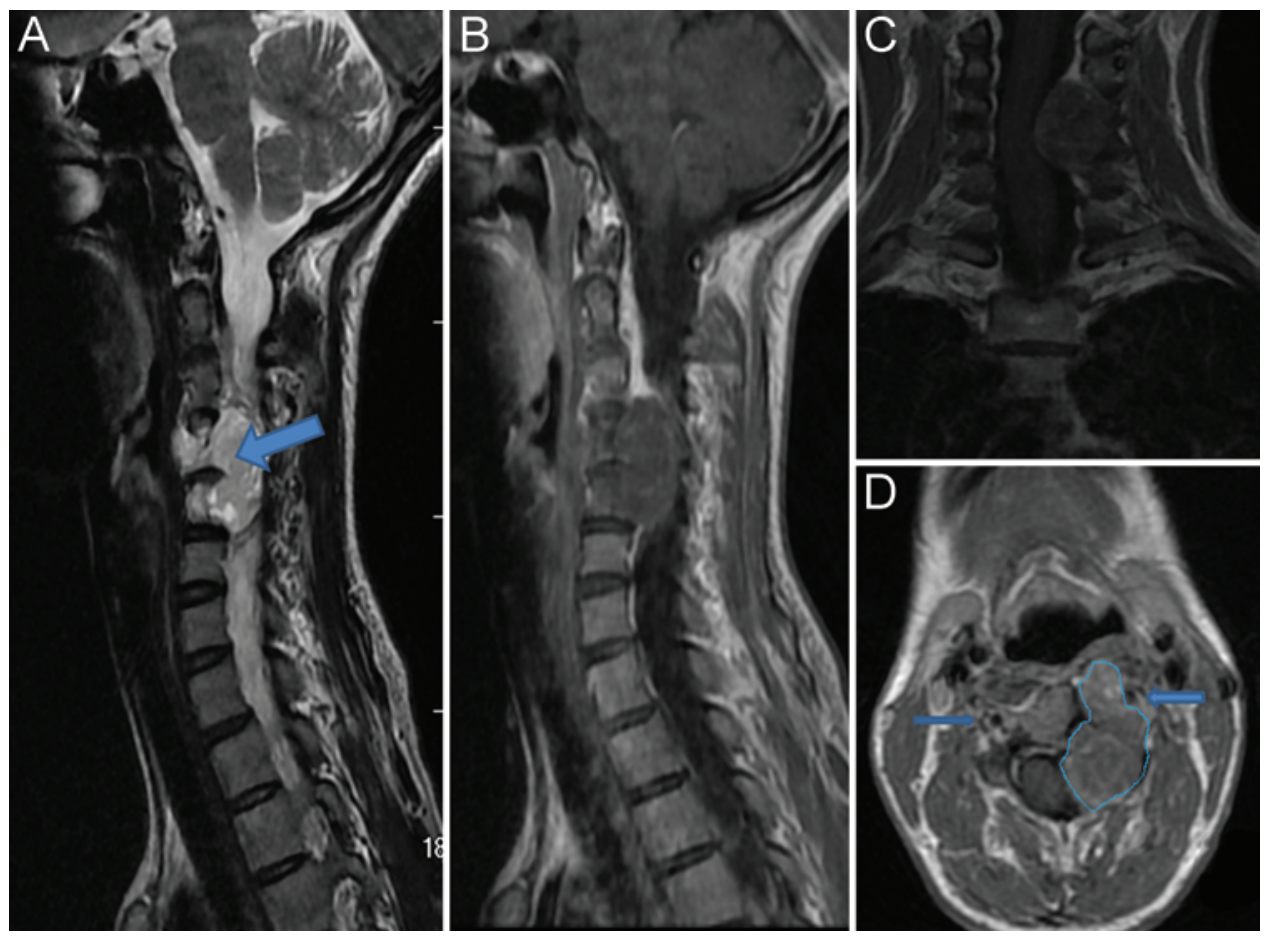

FIG. 2. Case 10. Magnetic resonance images showing an irregular lesion that is hyperintense on T2-weighted images (A, arrow) and isointense on T1-weighted images (B) at the C4-5 vertebral level. The tumor heterogeneously strongly enhanced after Gd-DTPA administration; the mass extends to the left intervertebral foramen and involves the left vertebral body. The left vertebral artery significantly shifts due to the lesion ( $\mathbf{C}$ and $\mathbf{D}$, the left arrow; the right arrow shows the normal vertebral artery and the lesion is within the solid line). Figure is available in color online only. 


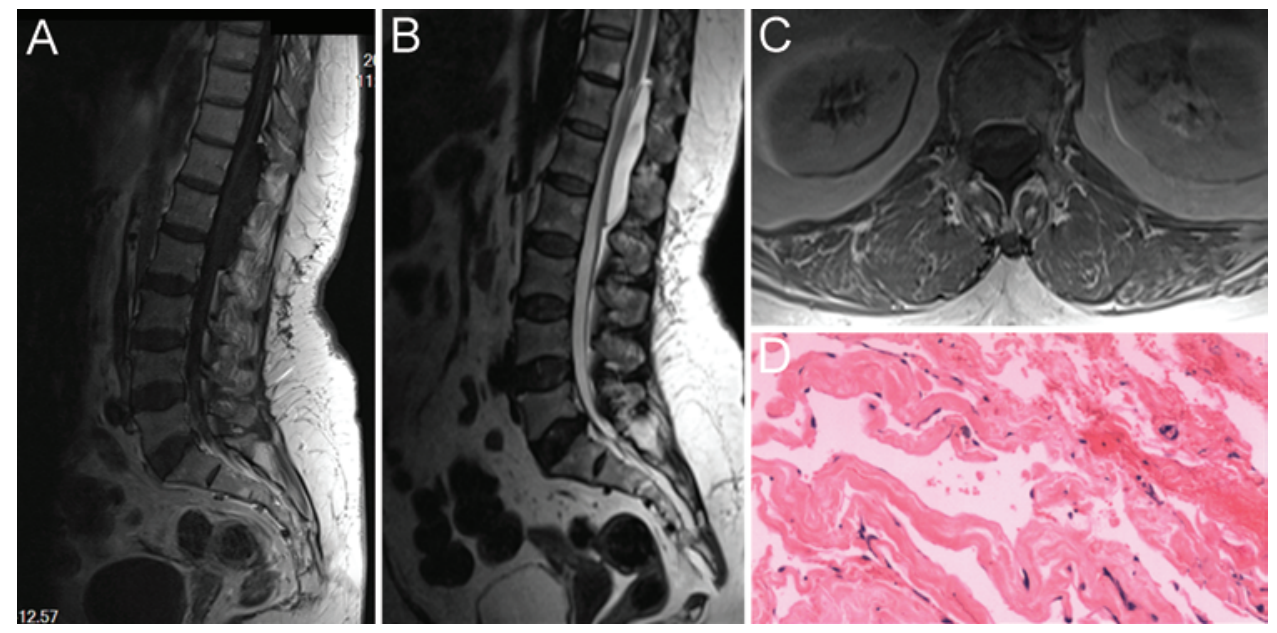

FIG. 3. Case 13. Magnetic resonance images and a photomicrograph of a large cystic mass at T12-L2. The lesion appears homogeneously hypointense on T1-weighted (A) and hyperintense on T2-weighted $(B)$ images. The lesion extends to the bilateral intervertebral foramina (C). The photomicrograph shows a cavernous hemangioma (D). Figure is available in color online only.

be caused by repeated bleeding and absorption, eventually leading to symptoms due to increasing tumor volume. A large amount of epidural hemorrhage usually results in acute spinal cord compression symptoms. ${ }^{4,9}$ In patients with small- to moderate-sized epidural hematomas, as the hematoma is absorbed over time, patients can experience spontaneous symptom relief, thus causing confusion with multiple sclerosis and spinal cord inflammatory disorders if MRI is not performed in a timely fashion. A large amount of acute hemorrhage often leads to severe cord damage; even prompt emergency surgical decompression cannot reverse all preoperative myelopathic symptoms. Acute bleeding can be triggered by trauma, heavy exercise, and use of anticoagulants, and it can also happen without any predisposing events. In general, the initial symptom was a sudden onset of severe local pain, followed by rapid development of paralysis, sensory level, and urinary/fecal incontinence.

Generally, intraspinal vascular lesions can be divided into vascular tumors (hemangioblastoma and cavernous malformation) and arteriovenous malformations. They can also be divided into epidural and intradural lesions. Epidural lesions frequently possess rich vascularity, which can lead to more rapid absorption of hemosiderin. Thus, the hemosiderin rings that are commonly associated with intraparenchymal cavernous malformation are less frequently seen in patients with epidural cavernous lesions. Based on MRI characteristics, spinal epidural vascular lesions can be categorized into 4 types: arteriovenous type with an organized hematoma, venous type, cavernous type, and cavernous type with hematoma. ${ }^{10}$ Digital subtraction angiography (DSA) has no role in the management of epidural cavernous hemangiomas, ${ }^{7,12}$ since these lesions fail to show up on angiography and cannot be embolized; however, DSA can be helpful in ruling out other types of spinal vascular malformations. Arteriovenous malformations usually show flow void signal on MR images due to highvelocity blood flow.

In our study, 10 of the 14 lesions were located in the dorsal spinal canal, which may reflect the fact that there
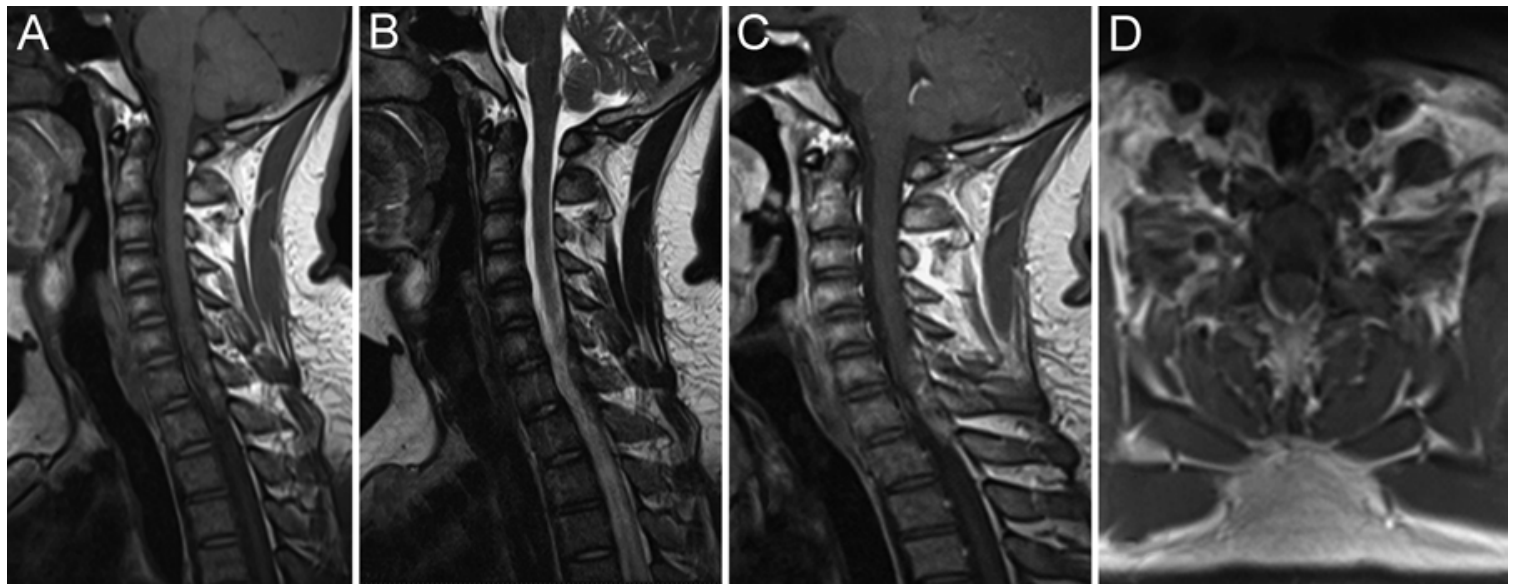

FIG. 4. Case 9. Magnetic resonance images obtained in a patient with a perilesional/epidural hematoma. The tumor shows different MRI signals on T1-weighted (A) and T2-weighted (B) images. Heterogeneous enhancement is seen after Gd-DTPA administration on sagittal (C) and axial (D) images caused by tumor hemorrhage or liquefaction of the hematoma or intravascular thrombosis. 
TABLE 4. Postoperative follow-up with Frankel's grade

\begin{tabular}{ccccc}
\hline & Follow-Up & \multicolumn{3}{c}{ Frankel Grade } \\
\cline { 3 - 5 } Case No. & (mos) & Preop & Postop & Follow-Up \\
\hline 1 & 53 & $\mathrm{D}$ & $\mathrm{D}$ & $\mathrm{E}$ \\
\hline 4 & 42 & $\mathrm{~A}$ & $\mathrm{~A}$ & $\mathrm{~A}$ \\
\hline 5 & 9 & $\mathrm{~A}$ & $\mathrm{~A}$ & $\mathrm{~A}$ \\
\hline 6 & 62 & $\mathrm{D}$ & $\mathrm{D}$ & $\mathrm{E}$ \\
\hline 7 & 48 & $\mathrm{D}$ & $\mathrm{D}$ & $\mathrm{E}$ \\
\hline 8 & 46 & $\mathrm{C}$ & $\mathrm{C}$ & Dead \\
\hline 9 & 38 & $\mathrm{D}$ & $\mathrm{D}$ & $\mathrm{E}$ \\
\hline 10 & 26 & $\mathrm{E}$ & $\mathrm{E}$ & $\mathrm{E}$ \\
\hline 11 & 10 & $\mathrm{D}$ & $\mathrm{D}$ & $\mathrm{E}$ \\
\hline 14 & 6 & $\mathrm{~A}$ & $\mathrm{~A}$ & $\mathrm{~A}$ \\
\hline
\end{tabular}

is more space in the dorsal canal, ${ }^{9}$ as well as the plastic nature of the softtexture cavernous hemangioma. ${ }^{3}$ In 9 cases, the tumors grew into the intervertebral foramen, which may be due to the loose tissue structure inside the neuroforamen. ${ }^{2,16,17}$ On average, 2.5 vertebral segments were involved in each case, suggesting that epidural cavernous hemangiomas more likely tend to grow laterally than longitudinally. Bone destruction was found in 5 cases (and in all 3 cases of recurrence). Pure epidural cavernous hemangiomas occasionally can cause bone destruction, although in our study bone destruction was more commonly seen in cases of recurrence, which may be explained by the previous surgery or simply because patients who experienced recurrence harbored the tumor for a long time. Three patients had extraforaminal components that were larger than the intracanal tumors. All 3 of these lesions were located in the thoracic spine; the negative thoracic cavity pressure may facilitate the growth of the cavernous hemangioma toward the pleural cavity. Intramedullary high signal intensity was found in 3 cases and was usually associated with high-degree cord compression due to tumor hemorrhage or fast growth; this finding is an independent negative prognostic sign.

Primary epidural cavernous hemangioma is a relatively rare clinical entity, and precise preoperative diagnosis is difficult except in cases of recurrence or those associated with hematoma. In most of our patients, the tumor is isointense on T1-weighted images and hyperintense on T2weighted images; the tumor signal is slightly lower than that of water (10 of 14 cases). Tumors with hemorrhage, liquefaction of the hematoma, or intravascular thrombosis can have different signals on MRI or heterogeneous enhancement. ${ }^{917}$ Primary epidural cavernous hemangiomas share many common imaging features with schwannomas and meningiomas; however, we believe the following features can help to distinguish these lesions from other common spinal lesions. Cavernous hemangiomas can grow into multiple-level or bilateral neuroforamina (5/14); when they do extend through the foramen as a dumbbell-shaped lesion, they do not enlarge the neuroforamen as much as a schwannoma or neurofibroma of similar size, and they often have an irregular or lobulated contour with strong enhancement. Schwannomas enhance less after admin- istration of contrast medium and frequently have cystic changes. Clinically, less radicular pain or spontaneously resolved radicular pain in the presence of a large intraforaminal lesion is a rule for epidural cavernous hemangioma. A peripheral rim, shown as atypical hypodensity on both T1- and T2-weighted images and caused by hemosiderin deposits from previous intralesional bleeding, can be seen on MRI. Lymphoma usually appears isointense on T2-weighted images and exhibits less frequent paravertebral extension and intervertebral neural foraminal widening. An angiolipoma is typically hyperintense on T1-weighted images because of its fat content, while the fat in a cavernous hemangioma is usually absent.

In this study, all 3 recurrent tumors were large and tightly adhered to surrounding tissue with unclear tumor borders. Bony destruction was seen in all 3 cases. We failed to achieve a total resection in 2 cases; recurrent tumor seems to be the most important hindrance in achieving total resection, although there are reports that total resection still can be achieved by elaborate microscopic surgery in cases of recurrent epidural cavernous hemangioma. ${ }^{1,3,12}$

Complete resection is currently the best treatment for epidural cavernous hemangiomas. ${ }^{9,17}$ During surgery, whenever a hypervascular lesion encroaches onto the dura mater with a soft, purple tumor mass extending through the foramen, an epidural cavernous hemangioma should be strongly suspected. Tumor biopsy should be avoided. The first step of surgery should be bipolar coagulation to disrupt the abnormal proliferation of blood vessels and feeding arteries (root artery and its branches), followed by coagulation of the thickened draining veins. Electrocoagulation can greatly shrink the cavernous hemangioma, thereby reducing the unpredictable intraoperative bleeding ${ }^{15}$ and facilitate the separation of the tumor. En bloc resection is the preferred surgical strategy, although it is impossible in cases in which the tumor extends beyond the neuroforamen. In cases in which piecemeal resection has to be done, tightly packed Gelfoam roll compression is quite effective for hemostasis. Cavernous hemangiomas can often encase the spinal nerve root inside the canal. When the tumors are dissected away from nerve root, the tumor mass is violated and intense bleeding can be encountered. We prefer to use Cottonoids to push the tumor toward the neuroforamen. When tumor dissection is completed, some intractable hemorrhage may be caused by bony erosion; this should be promptly recognized and managed with bone wax rather than electrocautery.

We routinely use the lateral position with the tumor side up. This position also helps to clear the operative field and control vigorous intraoperative bleeding. The lateral position also reduces epidural venous pressure in the vertebral canal due to the reduced chest and abdominal compression. For dumbbell-shaped large tumors, we prefer to perform a laminectomy and only partial medial facetectomy, without disrupting the osseous continuity of the interarticularis, thereby avoiding spinal fusion and fixation. ${ }^{16}$ The extraforaminal tumor can be removed through a separate lateral approach.

In patients with an acute symptom onset due to hemorrhage, DSA can be done to rule out other vascular malformations if the patient's condition allows, but DSA cannot 
diagnose epidural cavernous hemangiomas definitively. In the face of acute paraplegia, an urgent exploratory laminectomy/decompression should be done, and DSA should not delay the surgery. ${ }^{13}$

For patients with lesions growing into the pleural cavity or adjacent vital structures (such as the vertebral artery), total resection should not be forced to avoid serious complications. ${ }^{2}$ In cases of incomplete resection, radiation therapy has been suggested to control the tumor growth, Sohn et al. suggested performing stereotactic radiotherapy (32 Gy in 4 fractions). ${ }^{14}$ The authors reported on 1 patient with a thoracic intraforaminal lesion. At the 3 -year followup, the tumor showed no evidence of growth. The use of radiation therapy remains a controversial issue since the natural history of epidural cavernous hemangioma is still unclear, and the therapeutic effect of radiation therefore cannot be determined from this limited number of cases.

Ten patients were followed up with a median of 36 months after the operation. One patient died, 5 patients demonstrated significant clinical improvement, and 4 patients remained neurologically unchanged. In 2 cases of subtotal resection and 2 cases of partial resection with an average follow-up of 36.5 months, there has been no symptom progression, and the tumor size has remained stable on the follow-up MRI imaging, indicating slow tumor growth. One patient died of pulmonary complications, and all other patients remained neurologically stable or showed improvement during the follow-up period. These results prove that the operations were effective., ${ }^{9,17}$ The preoperative neurological condition seemed to be the most important prognostic factor in our group of patients. Since the surgery is safe and effective and paralysis due to acute hemorrhage is known to adversely affect the outcome, it is worth evaluating whether we should consider surgical options in asymptomatic patients with large epidural cavernous hemangiomas. A better study on the natural history of this disorder can help us to answer this question.

\section{Conclusions}

Total surgical removal of primary spinal epidural cavernous hemangiomas with a chronic course is the optimum treatment and has a good prognosis. Additional surgery for recurrent tumors is technically more challenging, and total resection may not be possible; however, partial tumor resection and decompression can still reverse patients' symptoms. The preoperative neurological condition is the most important prognostic factor. In patients with acute paralysis due to hemorrhage, even an emergency decompression and complete tumor resection cannot lead to complete recovery.

\section{References}

1. Aoyagi N, Kojima K, Kasai H: Review of spinal epidural cavernous hemangioma. Neurol Med Chir (Tokyo) 43:471-476, 2003

2. Badinand B, Morel C, Kopp N, Tran Min VA, Cotton F: Dumbbell-shaped epidural capillary hemangioma. AJNR Am J Neuroradiol 24:190-192, 2003

3. Feng J, Xu YK, Li L, Yang RM, Ye XH, Zhang N, et al: MRI diagnosis and preoperative evaluation for pure epidural cavernous hemangiomas. Neuroradiology 51:741-747, 2009

4. Floeth F, Riemenschneider M, Herdmann J: Intralesional hemorrhage and thrombosis without rupture in a pure spinal epidural cavernous angioma: a rare cause of acute lumbal radiculopathy. Eur Spine J 19 (Suppl 2):S193-S196, 2010

5. Frankel HL, Hancock DO, Hyslop G, Melzak J, Michaelis $\mathrm{LS}$, Ungar GH, et al: The value of postural reduction in the initial management of closed injuries of the spine with paraplegia and tetraplegia. I. Paraplegia 7:179-192, 1969

6. Goyal A, Singh AK, Gupta V, Tatke M: Spinal epidural cavernous haemangioma: a case report and review of literature. Spinal Cord 40:200-202, 2002

7. Hasan A, Guiot MC, Torres C, Marcoux J: A case of a spinal epidural capillary hemangioma: case report. Neurosurgery 68:E850-E853, 2011

8. Hakan T, Demir M, Aker F, Berkman M: Pregnancy-related spinal epidural capillary-cavernous haemangioma: magnetic resonance imaging and differential diagnosis. Australas Radiol 51:B6-B9, 2007

9. Hatiboglu MA, Iplikcioglu AC, Ozcan D: Epidural spinal cavernous hemangioma. Neurol Med Chir (Tokyo) 46:455458,2006

10. Lee JW, Cho EY, Hong SH, Chung HW, Kim JH, Chang KH, et al: Spinal epidural hemangiomas: various types of MR imaging features with histopathologic correlation. AJNR Am J Neuroradiol 28:1242-1248, 2007

11. Nagi S, Megdiche H, Bouzaïdi K, Haouet S, Khouja N, Douira W, et al: Imaging features of spinal epidural cavernous malformations. J Neuroradiol 31:208-213, 2004

12. Rahman A, Hoque SU, Bhandari PB, Abu Obaida AS: Spinal extradural cavernous haemangioma in an elderly man. BMJ Case Rep 2012:bcr-2012006453, 2012

13. Sarikaya-Seiwert S, Gierga K, Wessalowski R, Steiger HJ, Hänggi D: Solitary spinal epidural cavernous angiomas in children presenting with acute neurological symptoms caused by hemorrhage. Report of 2 cases. J Neurosurg Pediatr 5:89-93, 2010

14. Sohn MJ, Lee DJ, Jeon SR, Khang SK: Spinal radiosurgical treatment for thoracic epidural cavernous hemangioma presenting as radiculomyelopathy: technical case report. Neurosurgery 64:E1202-E1203, 2009

15. Talacchi A, Spinnato S, Alessandrini F, Iuzzolino P, Bricolo A: Radiologic and surgical aspects of pure spinal epidural cavernous angiomas. Report on 5 cases and review of the literature. Surg Neurol 52:198-203, 1999

16. Uchida K, Yayama T, Nakajima H, Hirai T, Kobayashi S, Chen K, et al: Microsurgical resection of cavernous haemangioma around the thoracic neuroforamen: a case report. J Orthop Surg (Hong Kong) 18:370-373, 2010

17. Zhong W, Huang S, Chen H, Sun H, Cai B, Liu Y, et al: Pure spinal epidural cavernous hemangioma. Acta Neurochir (Wien) 154:739-745, 2012

\section{Author Contributions}

Conception and design: G Wang, JJ Wang. Acquisition of data: Li. Analysis and interpretation of data: Li, Xu, JJ Wang. Drafting the article: Li. Critically revising the article: all authors. Reviewed submitted version of manuscript: all authors. Approved the final version of the manuscript on behalf of all authors: G Wang. Statistical analysis: Li. Administrative/technical/material support: G Wang, Xu, Yang, JJ Wang. Study supervision: G Wang, Yang, JJ Wang.

\section{Correspondence}

James Wang, Department of Neurosurgery, Providence Hospital, Seattle, Washington; Beijing Neurosurgery Institute, Tiantan Hospital, Tiantan Xili 6, Chongwen District, Beijing 1100050, China.email: dr.jjwang@gmail.com. 